\title{
IVIIII Health Literacy as a Social Determinant of Health in Asian American Immigrants: Findings from a Population-Based Survey in California
}

Hee Yun Lee, PhD, MSW, MSG' ', Taeho Greg Rhee, $A M^{2}$, Nam Keol Kim, MA ${ }^{3}$, and Jasjit S. Ahluwalia, $M D, M P H, M S^{4}$

${ }^{1} S c h o o l$ of Social Work, College of Education and Human Development, University of Minnesota, Twin Cities, MN, USA; ${ }^{2}$ Department of Pharmaceutical Care and Health Systems, College of Pharmacy, University of Minnesota, Minneapolis, MN, USA; ${ }^{3}$ Department of Educational Psychology, College of Education and Human Development, University of Minnesota, Minneapolis, MN, USA; ${ }^{4}$ Center for Health Equity, Clinical and Translational Sciences Institute, University of Minnesota Medical School, Minneapolis, MN, USA.

BACKGROUND: Asian American immigrants have a lower level of health literacy than non-Latino whites, but their level of health literacy and its impact on health outcomes may differ among subgroups.

OBJECTIVE: We investigated the level of health literacy across five subgroups of Asian American immigrants and explored the association between health literacy and selfrated health status and symptoms of depression.

DESIGN: We utilized a cross-sectional survey research design and a population-based sampling strategy using the 2007 California Health Interview Survey (CHIS).

PARTICIPANTS: We sampled 30,615 non-Latino whites and 3,053 Asian American immigrants (1,058 Chinese, 598 Koreans, 534 Filipinos, 416 South Asians, and 447 Vietnamese).

MAIN MEASURES: We used two questions as proxy measures to assess the level of health literacy in non-Latino whites and in both aggregated and disaggregated Asian American immigrant groups. We then investigated the effect of health literacy on two main health outcomes: self-rated health status and depression symptoms.

KEY RESULTS: The level of health literacy varied across the five subgroups of Asian American immigrants. Chinese, Korean, and Vietnamese groups had the lowest levels of health literacy, while Filipinos showed the highest level. Health literacy was positively correlated with health status in Chinese and Korean immigrants, and negatively correlated with depression symptoms in Korean and South Asian immigrants.

CONCLUSION: We found heterogeneity in health literacy among Asian American immigrants and found that health literacy had varying associations with health outcomes. The aggregated Asian American immigrant group results may mask the true health disparities that each Asian American immigrant group faces. Koreans were the only group found to have a significant association between the proxy for health literacy and both health outcomes. Further research is needed to better understand the causes of heterogeneity and to investigate health literacy as a critical determinant of immigrant health.

Received February 19, 2014

Revised July 11, 2014

Accepted January 26, 2015

Published online February 26, 2015
KEY WORDS: health literacy; health status; depression; Asian American immigrants; health disparity.

J Gen Intern Med 30(8):1118-24

DOI: $10.1007 / \mathrm{s} 11606-015-3217-6$

(C) Society of General Internal Medicine 2015

\section{INTRODUCTION}

Immigrant populations are among the groups most vulnerable to health disparities in the United States. ${ }^{1,2}$ One of the major contributors to these disparities is health literacy, ${ }^{2,3}$ which is defined as "the degree to which individuals have the capacity to obtain, process, and understand basic health information and services needed to make appropriate health decisions." ${ }^{4(p . ~ 2)}$ Combined with linguistic and cultural barriers, health literacy is a critical determinant of immigrant health, as it provides individuals with the motivation and ability to understand and use information to promote their health or manage health conditions. ${ }^{5}$ Limited health literacy is associated with a lack of knowledge about health services, and this leaves individual immigrants vulnerable to underutilization of necessary medical care. ${ }^{5,6}$ For example, limited health literacy negatively affects the use of preventive services, ${ }^{7,8}$ adherence to medical instructions, ${ }^{9,10}$ and self-management skills. ${ }^{11}$

For immigrants, health literacy is closely associated with their English proficiency and their cultural health beliefs. For example, Sentell and Braun reported a prevalence of low health literacy among immigrants with limited English proficiency, and found that individuals with both low health literacy and limited English proficiency were more likely to have poorer health outcomes. ${ }^{3}$ Cultural beliefs also shape health literacy. One study that examined cultural influences on health literacy, cancer screening, and chronic disease morbidity reported that immigrants' cultural beliefs can affect how they understand and behave in response to their care providers' instructions. ${ }^{12}$ For instance, lower health literacy may hamper doctor-patient communication and lead to poor chronic disease management. ${ }^{12}$ These studies suggest that health care providers should recognize that health literacy affects health outcomes and should consider how health literacy can be 
affected by a patient's English proficiency and cultural background.

A growing body of literature has examined health literacy and its impact on health outcomes. Schillinger and colleagues found that, when controlling for other associated factors, inadequate health literacy was significantly associated with poorer self-rated health status among patients with diabetes. ${ }^{11}$ Two other studies also support the finding that inadequate health literacy may contribute to poorer health status. ${ }^{10,13}$ Other studies have shown that a lower health literacy level is closely related to a greater number of depression symptoms among adults with addiction. ${ }^{14,15}$

Despite these findings, the role of health literacy on health outcomes among immigrant populations has been understudied. Studies that do exist have typically focused on a single immigrant population group with a single health outcome variable. For example, one study that investigated predictors of and pathways to health literacy ${ }^{16}$ included only Korean Americans. In this study, a higher level of education and having health insurance were found to be strongly associated with a higher level of health literacy. Kim and Yu, who also focused on a single ethnic group, found that Korean older adults with a lower level of health literacy were more likely to have poorer physical and mental health conditions. ${ }^{17}$ Coffman and Norton studied health literacy and depression among Latino immigrants and concluded that new Latino immigrants were more likely to have lower health literacy, be depressed, and have lack of access to health care. ${ }^{18}$

Although Asian American immigrants (hereafter referred to as Asian immigrants) as a whole may have a lower level of health literacy than non-Latino whites, ${ }^{1,2}$ little is known about the levels of health literacy among distinct ethnic groups of Asian immigrants. Furthermore, to our knowledge, no study has explored how health literacy across different subgroups of Asian immigrant populations has an impact on different health outcomes. The majority of previous studies ${ }^{7,8,10,11}$ have investigated the relationship between health literacy and self-rated health or depression. While self-rated health status is widely used in population surveys and has been shown to be a powerful predictor of morbidity and mortality, ${ }^{19}$ symptoms of depression have been used comprehensively to assess psychological distress and well-being in Asian immigrants. ${ }^{20}$ Our objectives in this study, therefore, were (1) to identify the levels of health literacy among five subgroups of Asian immigrants, and to compare these to the aggregated Asian immigrant group and non-Latino whites; and (2) to determine the affect of health literacy on two health outcomes, self-rated health status and depression symptoms, across these five subgroups of Asian immigrants when controlling for other relevant covariates. We hypothesized that the aggregated Asian immigrant group would have a lower level of health literacy than its non-Latino white counterpart. We further posited that heterogeneity among subgroups of Asian immigrants would lead to varying levels of health literacy. For example, Filipinos speak English as a native language, while
Koreans and Chinese do not. Such language barriers might affect the capacity of certain subgroups to obtain, process, and use health information. We also hypothesized that those with a higher level of health literacy would have higher self-rated health status and lower levels of depression symptoms than their counterparts.

\section{METHODS \\ Research Design and Data Source}

The study used data collected from the 2007 California Health Interview Survey (CHIS). The CHIS is a telephone survey of the non-institutionalized population residing in California. It is administered in five languages (English, Spanish, Chinese [Mandarin and Cantonese], Korean, and Vietnamese), with oversampling of Asian Americans, ${ }^{21}$ as $40 \%$ of Asian Americans in the U.S. reside in California. ${ }^{22}$ The 2007 dataset contains detailed questionnaires related to health literacy, as well as health conditions and health-related behaviors. The original sample included 51,408 adult participants aged 18 years and over, but our study sample comprised 33,668 participants, as we excluded non-Latino whites born outside the U.S., African Americans, and Latino Americans. Included in our sample were Asian Americans born outside the U.S. as an aggregated group and U.S.-born non-Latino whites. We excluded Japanese Americans due to a limited immigrant sample size. $^{3}$ The sample was then categorized into five subgroups: Chinese, Korean, Filipino, South Asian, and Vietnamese American groups (hereafter referred to as Chinese, Korean, Filipino, South Asian, and Vietnamese), with the non-Latino white group as the reference group. Overall, the sample comprised 30,615 non-Latino whites and 3,053 Asian immigrants (1,058 Chinese, 598 Koreans, 534 Filipinos, 416 South Asians, and 447 Vietnamese).

\section{Instruments}

Dependent Variables. Self-Rated Health Status. For selfrated health status, each participant self-reported his or her health status using a five-point Likert scale ranging from poor (1) to excellent (5).

Depression Symptoms. The CHIS contained six items asking about depression symptoms within the past 30 days, which were adapted from Kessler's psychological distress scale, ${ }^{23}$ with responses to each item based on a five-point Likert scale ranging from all (1) to none (5). We re-coded these responses in the opposite direction such that a higher score indicated greater depression symptoms. We constructed a variable by transforming ordinal responses to these six items into one latent trait score using the graded response model (GRM) ${ }^{24}$ After the transformation, the score ranged from -3.43 to 4.70 . This score was then linearly transformed to a range of 0 to 10 , with 10 indicating the highest number of depression 
symptoms. We used Winsteps software version $3.65^{25}$ for this procedure. A transformation process using the item response theory (IRT) allowed us to overcome (1) potentially unequal intervals between response categories in the Likert-type rating scales and (2) issues associated with missing responses using maximum likelihood estimates. ${ }^{26}$

Independent Variables. Health Literacy. The 2007 CHIS included two items assessing health literacy. The first question was, "When you read the instructions on your prescription bottle, would you say it is very easy (1), somewhat easy (2), somewhat difficult (3), or very difficult (4) to understand?" The second question asked, "When you get your written information at a doctor's office, would you say that it is very easy (1), somewhat easy (2), somewhat difficult (3), or very difficult (4) to understand?" While we acknowledge that these questions may capture only one aspect of health literacy, they were used as proxy measures for health literacy ${ }^{3}$ in the Commonwealth Fund 2006 Health Care Quality Survey ${ }^{27}$ and the 2009 Health Research for Action Health Care Access Project. ${ }^{28}$ We re-coded the responses in the opposite direction such that a higher score in response to these questions indicated a higher level of health literacy. We used the IRT to construct the health literacy variable ranging from 0 to 10 , following the same procedure as explained above.

Control Variables. This study included a number of control variables. Continuous variables included age, educational attainment, and frequency of doctor visits per year. Categorical variables included gender, disability, limited English proficiency (LEP), and marital status. We controlled for severity of chronic conditions by summing the frequency of four chronic conditions, including asthma, diabetes, blood pressure, and heart disease, that were measured in the survey. Other controlling variables included health insurance status, number of years of being in the U.S., living in a rural area, and poverty level.

Data Analysis. First, we presented a univariate analysis to compare the levels of health literacy among non-Latino whites, Asian immigrants as an aggregated group, and the five different ethnic subgroups of Asian immigrants, using IBM SPSS software version $20.0 .^{29}$ Second, to investigate whether health literacy differed across these groups, we used the $t$-test for regression coefficients from simple regression analyses repeatedly with different ethnicity dummy variables $(0=$ nonLatino whites, $1=$ each Asian immigrant group) with weighted health literacy values. Lastly, multiple regression analyses on health status and depression symptoms with health literacy using appropriate weights in each ethnic group were conducted. We entered health literacy as the last variable in these models to see if it was a significant contributor for health status and/or depression symptoms, when controlling for all other covariates. Due to the nature of complex sample design of the CHIS, this study used replicated weighting methods using Stata software version $12.0^{30}$ that enabled us to produce unbiased estimates using a valid variance estimation.

\section{RESULTS}

Table 1 presents sociodemographic characteristics of the population of the study sample. Asian immigrants were younger (50.26 years old) than non-Latino whites (57.39). The frequency of doctor visits among non-Latino whites was 5.42 times a year, higher than any Asian group. Koreans had the highest depression symptoms score (2.73), whereas Chinese had the lowest (2.17). $85.81 \%$ of South Asians reported that their income was higher than $200 \%$ of federal poverty line on average. Koreans had the largest percent of limited English proficiency $(58.19 \%)$, whereas South Asians had the smallest proportion $(3.13 \%)$. Koreans were the least likely to be fully insured in the past 12 months $(69.40 \%)$.

Table 2 presents weighted health literacy levels across the different Asian immigrant groups. The Chinese group had the lowest mean health literacy score (6.00), while Filipinos had the highest mean score (8.48). In bivariate analysis, nonLatino whites had a significantly higher health literacy score than the Chinese $(b=-2.30, p<0.001)$, Korean $(b=-1.56$, $p<0.001)$, and Vietnamese $(\mathrm{b}=-1.76, p<0.001)$ groups, but there was no difference in health literacy score for nonLatino whites compared to Filipinos and South Asian groups.

Tables 3 and 4 present multiple regression analyses of the association between health literacy and health status/ depression symptoms. Health literacy was significantly associated with health status among non-Latino white and aggregated Asian immigrants groups $(p<0.01)$. However, when the latter group was disaggregated into five ethnic groups, only the Chinese and Korean groups showed health literacy as a significant predictor of self-rated health status $(p<0.05)$.

Health literacy was significantly associated with depression symptoms among non-Latino white and aggregated Asian immigrant groups $(p<0.01)$. However, when the latter group was disaggregated, only the Korean and South Asian groups showed health literacy as a significant factor for depression symptoms $(p<0.05)$.

\section{DISCUSSION}

This study investigated the levels of health literacy across five different Asian immigrant subgroups and the association between health literacy and different health outcomes. Our findings confirmed our first hypothesis, that varying levels of health literacy existed across five subgroups of Asian immigrants. On average, the mean health literacy score for nonLatino whites (8.30) was significantly higher than that of the aggregated Asian immigrant group (7.11) $(p<0.001)$. However, when Asian immigrant subgroups were disaggregated, 
Table 1 Sociodemographic Characteristics of Participants

\begin{tabular}{|c|c|c|c|c|c|c|c|c|}
\hline \multirow[t]{2}{*}{ Variables } & & \multicolumn{7}{|l|}{ Ethnicity } \\
\hline & & $\begin{array}{l}\text { Non-Latino } \\
\text { whites } \\
(N=30,615)\end{array}$ & $\begin{array}{l}\text { Aggregated } \\
\text { Asian } \\
\text { American } \\
\text { immigrants } \\
(N=\mathbf{3 , 0 5 3 )}\end{array}$ & $\begin{array}{l}\text { Chinese } \\
(N=\mathbf{1 , 0 5 8})\end{array}$ & $\begin{array}{l}\text { Korean } \\
(N=\mathbf{5 9 8})\end{array}$ & $\begin{array}{l}\text { Filipino } \\
(N=534)\end{array}$ & $\begin{array}{l}\text { South } \\
\text { Asian } \\
(N=416)\end{array}$ & $\begin{array}{l}\text { Vietnamese } \\
(N=447)\end{array}$ \\
\hline \multicolumn{9}{|l|}{ Continuous variable } \\
\hline \multicolumn{2}{|l|}{ Age } & 57.39 & 50.26 & 50.19 & 54.27 & 51.79 & 42.77 & 50.20 \\
\hline \multicolumn{2}{|c|}{ Gender $(\%$ male $)$} & 40 & 43 & 42 & 37 & 35 & 55 & 51 \\
\hline \multicolumn{2}{|c|}{ Marital status (\% married) } & 56 & 75 & 76 & 74 & 69 & 83 & 73 \\
\hline \multicolumn{2}{|c|}{ Frequency of doctor visits } & 5.42 & 3.37 & 3.00 & 3.85 & 3.26 & 3.29 & 3.83 \\
\hline \multicolumn{2}{|c|}{ Number of diseases } & 0.73 & 0.50 & 0.41 & 0.45 & 0.75 & 0.41 & 0.55 \\
\hline \multicolumn{2}{|c|}{ Disability (\% disabled) } & 37 & 25 & 18 & 24 & 31 & 16 & 45 \\
\hline \multicolumn{2}{|c|}{ Depression symptoms $(0-10)$} & 2.41 & 2.34 & 2.17 & 2.73 & 2.37 & 2.26 & 2.28 \\
\hline \multicolumn{9}{|c|}{ Categorical variable } \\
\hline \multirow[t]{4}{*}{ Education } & Lower than high school & 4.30 & 9.05 & 9.72 & 8.38 & 2.81 & 1.93 & 22.86 \\
\hline & High school & 21.43 & 16.48 & 14.68 & 23.25 & 11.42 & 7.97 & 26.10 \\
\hline & Some college & 54.51 & 50.95 & 44.33 & 54.87 & 73.22 & 41.55 & 43.19 \\
\hline & Graduate school & 19.76 & 23.52 & 31.27 & 13.50 & 12.55 & 48.55 & 7.85 \\
\hline \multirow[t]{4}{*}{ Poverty } & $\begin{array}{l}0-99 \% \text { of federal poverty } \\
\text { line (FPL) }\end{array}$ & 5.18 & 15.00 & 13.33 & 19.90 & 8.80 & 6.49 & 27.74 \\
\hline & $100-199 \%$ of FPL & 12.23 & 18.11 & 18.05 & 17.73 & 18.91 & 7.69 & 27.52 \\
\hline & $200299 \%$ of FPL & 13.15 & 11.86 & 11.81 & 13.88 & 13.67 & 8.65 & 10.07 \\
\hline & $300 \%$ of FPL and above & 69.44 & 55.03 & 56.81 & 48.49 & 58.61 & 77.16 & 34.68 \\
\hline \multirow{2}{*}{$\begin{array}{l}\text { Limited English } \\
\text { proficiency }\end{array}$} & Non-proficient & 0.04 & 32.46 & 35.07 & 58.19 & 5.43 & 3.13 & 51.45 \\
\hline & Proficient & 99.96 & 67.54 & 64.93 & 41.81 & 94.57 & 96.88 & 48.55 \\
\hline \multirow[t]{3}{*}{ Health insurance } & Currently uninsured & 6.15 & 14.25 & 11.06 & 26.76 & 11.05 & 7.69 & 14.99 \\
\hline & $\begin{array}{l}\text { Uninsured within the } \\
\text { past } 12 \text { months }\end{array}$ & 2.35 & 2.65 & 2.17 & 3.85 & 1.69 & 3.13 & 2.91 \\
\hline & $\begin{array}{l}\text { Insured within the } \\
\text { past } 12 \text { months }\end{array}$ & 91.50 & 83.10 & 86.77 & 69.40 & 87.27 & 89.18 & 82.10 \\
\hline \multirow[t]{5}{*}{ Health status } & Poor & 4.64 & 6.62 & 3.31 & 10.70 & 4.49 & 1.92 & 15.88 \\
\hline & Fair & 11.25 & 19.16 & 19.75 & 19.57 & 16.67 & 7.21 & 31.32 \\
\hline & Good & 26.61 & 31.87 & 33.36 & 35.12 & 31.65 & 29.57 & 26.40 \\
\hline & Very good & 35.80 & 26.04 & 30.15 & 16.72 & 31.84 & 32.93 & 15.44 \\
\hline & Excellent & 21.71 & 16.31 & 13.42 & 17.89 & 15.36 & 28.37 & 10.96 \\
\hline \multirow[t]{2}{*}{ Rurality } & $\begin{array}{l}\text { Urban, second city, and } \\
\text { suburban }\end{array}$ & 69.73 & 93.94 & 95.65 & 94.82 & 90.26 & 90.87 & 95.97 \\
\hline & Rural & 30.27 & 6.06 & 4.35 & 5.18 & 9.74 & 9.13 & 4.03 \\
\hline \multirow[t]{5}{*}{ Years in U.S. } & Less than 1 year & & 2.92 & 2.93 & 1.51 & 3.56 & 5.29 & 1.79 \\
\hline & $2-4$ years & & 6.22 & 6.05 & 8.19 & 4.12 & 7.93 & 4.92 \\
\hline & 5-9 years & $\mathrm{N} / \mathrm{A}$ & 11.96 & 12.10 & 12.04 & 9.55 & 20.19 & 6.71 \\
\hline & $10-14$ years & & 13.00 & 13.99 & 11.20 & 5.43 & 18.03 & 17.45 \\
\hline & More than 15 years & & 65.90 & 64.93 & 67.06 & 77.34 & 48.56 & 69.13 \\
\hline
\end{tabular}

health literacy fluctuated across the groups. For example, only Chinese (6.0), Korean (6.73), and Vietnamese (6.54) groups had significantly lower levels of health literacy than nonLatino whites, with the Filipino (8.48) group reporting the highest level of health literacy. These findings are consistent with a previous study demonstrating that these three Asian immigrant groups possess the lowest level of health literacy across Asian immigrant subgroups. ${ }^{3}$ This is not surprising considering their higher prevalence of limited English proficiency. ${ }^{31}$

Findings from the multiple regression models confirmed our second hypothesis, that Asian immigrants with a higher level of health literacy would have a higher self-rated health status and a lower level of depression symptoms than their

Table 2 Levels of Health Literacy Among Subgroups of Asian American Immigrants with Comparison to Non-Latino Whites

\begin{tabular}{|c|c|c|c|c|c|c|c|}
\hline & $\begin{array}{l}\text { Non-Latino } \\
\text { whites } \\
(N=\mathbf{3 0 , 6 1 5})\end{array}$ & $\begin{array}{l}\text { Aggregated } \\
\text { Asian American } \\
\text { immigrants } \\
(\boldsymbol{N}=\mathbf{3 , 0 5 3 )}\end{array}$ & $\begin{array}{l}\text { Chinese } \\
(N=\mathbf{1 , 0 5 8})\end{array}$ & $\begin{array}{l}\text { Korean } \\
(N=598)\end{array}$ & $\begin{array}{l}\text { Filipino } \\
(N=534)\end{array}$ & $\begin{array}{l}\text { South } \\
\text { Asian } \\
(N=416)\end{array}$ & $\begin{array}{l}\text { Vietnamese } \\
(N=447)\end{array}$ \\
\hline Mean $^{\mathrm{a}}$ & 8.30 & 7.11 & 6.00 & 6.73 & 8.48 & 8.08 & 6.54 \\
\hline Standard deviation & 2.18 & 2.85 & 3.18 & 2.88 & 2.05 & 2.22 & 2.39 \\
\hline 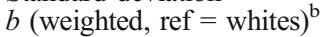 & & -1.19 & -2.30 & -1.56 & 0.18 & -0.21 & -1.76 \\
\hline$t$-statistic & & -14.40 & -14.19 & -7.72 & 1.25 & -1.27 & -10.08 \\
\hline$p$ value & & $<0.001$ & $<0.001$ & $<0.001$ & 0.215 & 0.208 & $<0.001$ \\
\hline
\end{tabular}

a. Health literacy scores on a scale from 0 to 10

b. Null hypothesis is that the regression coefficient of ethnicity dummy variable is equal to zero, which is to test weighted mean differences in a given dependent variable, health literacy. 
Table 3 Multiple Regression Analysis of the Affect of Health Literacy on Self-Reported Health Status

\begin{tabular}{|c|c|c|c|c|c|c|c|c|}
\hline Factors & Predictors & $\begin{array}{l}\text { Non- } \\
\text { Latino } \\
\text { whites }\end{array}$ & $\begin{array}{l}\text { Aggregated } \\
\text { Asian } \\
\text { American } \\
\text { immigrants }\end{array}$ & Chinese & Korean & Filipino & $\begin{array}{l}\text { South } \\
\text { Asian }\end{array}$ & Vietnamese \\
\hline \multirow{6}{*}{$\begin{array}{l}\text { Sociodemographic } \\
\text { factors }\end{array}$} & Age & $-0.005^{* *}$ & $-0.008^{* *}$ & -0.003 & -0.008 & -0.007 & $-0.020^{* *}$ & -0.014 \\
\hline & Gender (ref = female) & $-0.124^{* *}$ & 0.030 & -0.037 & 0.051 & 0.033 & 0.057 & 0.178 \\
\hline & Education & $0.054^{* *}$ & $0.036^{*}$ & 0.034 & $0.085^{* *}$ & -0.015 & 0.020 & -0.004 \\
\hline & Marital status (ref $=$ other) & 0.026 & -0.057 & -0.239 & 0.117 & -0.307 & $0.345^{*}$ & 0.162 \\
\hline & Poverty level & $0.018^{* *}$ & $0.026^{* *}$ & $0.031^{* *}$ & $0.044^{*}$ & 0.004 & 0.014 & 0.049 \\
\hline & Rural (ref = urban) & 0.016 & 0.056 & 0.200 & -0.371 & 0.148 & 0.005 & $-0.438^{*}$ \\
\hline \multirow{5}{*}{$\begin{array}{l}\text { Health access and mental } \\
\text { health factors }\end{array}$} & Insurance (ref = uninsured) & $0.063^{* *}$ & 0.054 & 0.091 & 0.020 & 0.090 & 0.004 & -0.061 \\
\hline & $\begin{array}{l}\text { Disability (ref }=\text { not } \\
\text { disabled) }\end{array}$ & $-0.539^{* *}$ & $-0.471^{* *}$ & $-0.221^{*}$ & -0.377 & $-0.649^{* *}$ & $-0.445^{* *}$ & -0.417 \\
\hline & Frequency of doctor visits & $-0.014^{* *}$ & $-0.036^{* *}$ & $-0.038^{* *}$ & $-0.058^{* *}$ & -0.019 & $-0.025^{*}$ & -0.023 \\
\hline & Number of diseases & $-0.339^{* *}$ & $-0.375^{* *}$ & $-0.469^{* *}$ & -0.164 & $-0.373^{* *}$ & $-0.405^{* *}$ & $-0.250^{* *}$ \\
\hline & Depression symptoms & $-0.120^{* *}$ & $-0.086^{* *}$ & $-0.104^{* *}$ & $-0.086^{*}$ & $-0.090^{*}$ & $-0.090^{* *}$ & -0.047 \\
\hline \multirow[t]{2}{*}{ Immigration factors } & Limited English proficiency & -0.046 & $0.155^{* *}$ & $0.127^{* *}$ & -0.038 & $0.154^{*}$ & 0.015 & $0.342^{* *}$ \\
\hline & Years in U.S. & $\mathrm{N} / \mathrm{A}$ & -0.005 & -0.006 & -0.000 & 0.019 & 0.015 & 0.052 \\
\hline Health literacy & & $0.011^{* *}$ & $0.034^{* *}$ & $0.030^{*}$ & $0.057^{*}$ & 0.040 & 0.037 & 0.012 \\
\hline Constant & & $4.246^{* *}$ & $3.099^{* *}$ & $2.929^{* *}$ & $3.479^{* *}$ & $3.313^{* *}$ & $4.192^{* *}$ & $3.086^{* *}$ \\
\hline$F$-statistic & & $522.19^{* *}$ & $59.03^{* *}$ & $21.23^{* *}$ & $15.91^{* *}$ & $12.89^{* *}$ & $13.46^{* *}$ & $17.13^{* *}$ \\
\hline$R$-squared & & 0.368 & 0.349 & 0.349 & 0.377 & 0.327 & 0.373 & 0.398 \\
\hline
\end{tabular}

$* p<0.05, * * p<0.01$

counterparts. For self-rated health status, health literacy played a significant role in the aggregated Asian immigrant group. However, when we disaggregated Asian immigrants into five groups, health literacy was significantly associated with selfrated health status only in the Chinese and Korean groups, with a positive association between health literacy and selfrated health status. This may reflect that Asian immigrants with limited health literacy are less likely to seek health care services (such as preventive services) or are unable to comply with treatment recommendations. If this is true, a higher level of health literacy would lead to higher and more appropriate use of health care services, and theoretically, better health status. Our finding confirms that of a previous study ${ }^{11}$ in which inadequate health literacy was reported to be significantly associated with worse health outcomes among patients with diabetes.
For depression symptoms, health literacy was a significant factor for the aggregated Asian immigrant group. Again, when the groups were disaggregated, health literacy was significantly related to depression symptoms only in Korean and South Asian groups. Unlike the relationship with self-rated health status, there was an inverse relationship between health literacy and depression symptoms. This finding is in line with previous studies, ${ }^{14,15}$ which reported that a lower level of health literacy was associated with worse depression symptoms. Asian immigrants with a lower level of health literacy may be less knowledgeable about preventive psychosocial care or mental health services available to treat depression, resulting in poorer mental health outcomes. Interestingly, no significant relationship was found in the Chinese group, which could be due to their unique cultural background and expression of depression symptoms. The Chinese generally adhere to

Table 4 Multiple Regression Analysis of the Affect of Health Literacy on Depression Symptoms

\begin{tabular}{|c|c|c|c|c|c|c|c|c|}
\hline Factors & Predictors & $\begin{array}{l}\text { Non- } \\
\text { Latino } \\
\text { whites }\end{array}$ & $\begin{array}{l}\text { Aggregated } \\
\text { Asian American } \\
\text { immigrants }\end{array}$ & Chinese & Korean & Filipino & $\begin{array}{l}\text { South } \\
\text { Asian }\end{array}$ & Vietnamese \\
\hline \multirow{6}{*}{$\begin{array}{l}\text { Sociodemographic } \\
\text { factors }\end{array}$} & Age & $-0.025^{* *}$ & $-0.042^{* *}$ & $-0.044^{* *}$ & -0.014 & $-0.047^{* *}$ & $-0.038^{* *}$ & $-0.045^{* *}$ \\
\hline & Gender (ref $=$ female) & $-0.230^{* *}$ & $-0.197^{*}$ & -0.226 & $-0.530^{*}$ & -0.171 & 0.102 & 0.091 \\
\hline & Education & $0.023^{* *}$ & 0.036 & $0.101^{* *}$ & 0.079 & -0.013 & -0.041 & -0.106 \\
\hline & Marital status (ref $=$ other) & $-0.097_{* *}^{* *}$ & $-0.401^{* *}$ & $-0.616^{* *}$ & -0.092 & -0.305 & -0.417 & -0.336 \\
\hline & Poverty level & $-0.016^{* *}$ & -0.012 & -0.009 & 0.002 & -0.010 & 0.003 & 0.025 \\
\hline & Rural (ref = urban) & -0.057 & 0.057 & -0.008 & -0.324 & -0.161 & $0.715^{*}$ & -0.374 \\
\hline \multirow{5}{*}{$\begin{array}{l}\text { Health access and } \\
\text { health status } \\
\text { factors }\end{array}$} & Insurance (ref $=$ uninsured) & $-0.169^{* *}$ & 0.015 & 0.222 & -0.040 & 0.010 & -0.044 & -0.141 \\
\hline & Disability (ref $=$ not disabled) & $0.624_{* * *}^{* *}$ & $0.844_{* *}^{* *}$ & $0.747^{* *}$ & $1.042_{* * *}^{* *}$ & $1.451^{* *}$ & -0.064 & 0.449 \\
\hline & Frequency of doctor visits & $0.012^{* *}$ & $0.030^{* *}$ & 0.032 & $0.066^{* *}$ & -0.003 & $0.047^{* *}$ & 0.004 \\
\hline & Number of diseases & 0.016 & 0.092 & 0.080 & $-0.073 *$ & 0.110 & 0.001 & 0.042 \\
\hline & Self-rated health status & $-0.357_{* *}^{* *}$ & $-0.267^{* *}$ & $-0.335^{* *}$ & $-0.220^{*}$ & $-0.252^{*}$ & $-0.346_{* *}^{* *}$ & -0.144 \\
\hline \multirow[t]{2}{*}{ Immigration factors } & Limited English proficiency & $-0.098^{*}$ & 0.058 & -0.015 & -0.036 & 0.142 & $-0.497^{* *}$ & 0.106 \\
\hline & Years in U.S. & $\mathrm{N} / \mathrm{A}$ & 0.106 & 0.050 & -0.152 & 0.095 & $0.219^{*}$ & 0.121 \\
\hline Health literacy & & $-0.095^{* *}$ & $-0.054^{* *}$ & -0.038 & $-0.082^{*}$ & -0.093 & $-0.114^{*}$ & -0.025 \\
\hline Constant & & $6.775^{* *}$ & $4.821_{* * *}^{* *}$ & $4.728^{* *}$ & $5.090^{* *}$ & $5.641^{* *}$ & $6.840^{* *}$ & $5.392^{* *}$ \\
\hline$F$-statistic & & $224.73^{* *}$ & $26.37^{* *}$ & $15.85^{* *}$ & $8.34^{* *}$ & $11.11^{* *}$ & $5.97^{* *}$ & $3.28^{* *}$ \\
\hline$R$-squared & & 0.211 & 0.191 & 0.263 & 0.245 & 0.296 & 0.215 & 0.139 \\
\hline
\end{tabular}

$* p<0.05, * * p<0.01$ 
Confucian values that emphasize modesty, emotional restraint, and social conformity, and this may have caused them to underreport symptoms of depression. ${ }^{32-34}$

Interestingly, despite the difference in levels of health literacy between the Filipino and Vietnamese groups, (8.48 and 6.54 , respectively), health literacy was not significantly associated with either self-reported health status or depression symptoms. We conducted post hoc power calculations after running multiple regression models in order to examine whether sample size could explain the insignificant link. However, we found that we had a sufficient sample size in each Asian group to conduct subgroup analyses. It is possible that in Filipino and Vietnamese groups, health literacy may not be an important factor for improving the two health outcomes, or that there may be other important reasons to explain the relationship between health literacy and the two health outcomes.

Our study also revealed that Koreans were the only group with a significant association between health literacy and both health outcomes. This finding demonstrates an urgent need for targeted intervention efforts oriented toward Korean ethnic groups to promote health literacy and thereby improve health outcomes. One way to improve health literacy among Koreans would be to provide health information (e.g., prescription bottles, written information, etc.) in native languages in clinical settings. Given that Koreans have the lowest overall English proficiency, this effort could have a critical impact on health outcomes. Developing and implementing community-based health literacy education programs offered in Korean may be another way to provide this group a better understanding of and better access to physical and mental health services in their own communities.

Several limitations should be noted for interpreting this study's findings. First, results may not be generalizable to Asian immigrants residing outside California. Second, variables in self-reported questionnaires such as health literacy, health status, and depression symptoms are subjective measures, and can lead to measurement biases such as recall bias. ${ }^{35}$ Moreover, responses to both self-perception of health and depression symptoms may have been influenced by cultural backgrounds. As has been noted previously among Chinese groups, if each ethnic group interpreted survey questions differently due to differences in cultural understanding, measurement errors would be unavoidable. Although the CHIS was conducted using reliable translated versions in multiple Asian languages for surveyed community members, ${ }^{21,22}$ cultural differences may still exist. Furthermore, it is possible that among Asian immigrants, the two questions used as proxies of health literacy could be measuring other issues such as general literacy, uncorrected vision problems, cognition, and language concordance, which may have led to differences among groups that are unrelated to health literacy.

Despite the limitations, our study advances existing literature with the findings that (1) heterogeneity clearly exists in levels of health literacy across different Asian immigrant groups and (2) health literacy affects health outcomes differently across Asian immigrant subgroups. For the aggregated Asian immigrant group, the level of health literacy (7.11) was significantly lower than that for non-Latino whites (8.30). However, when groups were disaggregated, only three of the five Asian immigrant groups were found to have lower health literacy levels than non-Latino whites. The variation may explain why Asian immigrants as a whole have lower health literacy levels than non-Latino whites. Moreover, while health literacy was significantly associated with both self-rated health status and depression symptoms among the aggregated Asian immigrant group, it was a significant factor for health outcomes only for Chinese, Koreans, and South Asians. This finding suggests that information generated from the aggregated Asian immigrant group may mask the true health disparities faced by each Asian immigrant group individually. Findings from disaggregated data enable us to prioritize our intervention efforts and give primary attention to these most vulnerable groups. Further research is needed to better understand the causes of such heterogeneity, as it can be critical to understanding the social determinants of immigrant health.

Funders: Funding for this research was provided by a grant from the Minnesota Agricultural Experiment Station (MIN-55-01).

Prior Presentations: None.

Conflict of Interest: The authors declare that they have no conflicts of interest.

Corresponding Author: Hee Yun Lee, PhD, MSW, MSG; School of Social Work, College of Education and Human Development, University of Minnesota, Twin Cities, MN, USA (e-mail: hylee@umn.edu).

\section{REFERENCES}

1. Kreps GL. Communication and racial inequities in health care. Am Behav Sci. 2006;49:760-774.

2. Kreps GL, Spark L. Meeting the health literacy needs of immigrant populations. Patient Educ Couns. 2008;71:328-332.

3. Sentell T, Braun KL. Low health literacy, limited English proficiency, and health status in Asians, Latinos, and other racial/ethnic groups in California. J Health Commun. 2012;17:82-99.

4. Nielsen-Bohlman L, Panzer AM, Kindig DA, eds. Health Literacy: A Prescription to End Confusion. Washington, DC: The National Academies Press, 2004.

5. Todd L, Hoffman-Goetz L. Predicting health literacy among English-as-asecond-language older Chinese immigrant women to Canada: Comprehension of colon cancer prevention information. $J$ Cancer Educ. 2011;26:326-332.

6. Nutbeam D. Health literacy as a public health goal: A challenge for contemporary health education and communication strategies into the 21 st century. Health Promot Int. 2000;15:259-267.

7. Davis TC, Dolan NC, Ferreira MR, Tomori C, Green KW, Sipler AM, Bennett CL. The role of inadequate health literacy skills in colorectal cancer screening. Cancer Invest. 2001;19:193-200.

8. Scott TL, Gazmararian JA, Williams MV, Baker DW. Health literacy and preventive health care use among Medicare enrollees in a managed care organization. Med Care. 2002;40:395-404.

9. DeWalt DA, Berkman ND, Sheridan S, Lohr KN, Pignone MP. Literacy and health outcomes: A systematic review of the literature. J Gen Intern Med. 2004; 19:1228-1239.

10. Wolf MS, Gazmararian JA, Baker DW. Health literacy and health risk behaviors among older adults. Am J Prev Med. 2007;32:19-24. 
11. Schillinger D, Grumbach K, Piette J, Wang F, Osmond D, Daher C, Palacios J, Sullivan GD, Bindman AB. Association of health literacy with diabetes outcomes. J Am Med Assn. 2002;288:475-482.

12. Shaw SJ, Huebner C, Armin J, Orzech K, Vivian J. The role of culture in health literacy and chronic disease screening and management. J Immigr Minor Health. 2009;11:460-467.

13. Weiss BD, Hart G, McGee DL, D'Estelle S. Health status of illiterate adults: relation between literacy and health status among persons with low literacy skills. J Am Board Fam Pract. 1992;5:257-264.

14. Lincoln A, Paasche-Orlow MK, Cheng DM, Lloyd-Travaglini C, Caruso C, Saitz R, Samet JH. Impact of health literacy on depressive symptoms and mental health-related quality of life among adults with addiction. J Gen Intern Med. 2006;21:818-822.

15. Lincoln A, Espejo D, Johnson P, Paasche-Orlow M, Speckman JL, Webber TL, White RF. Limited literacy and psychiatric disorders among users of an urban safety-net hospital's mental health outpatient clinic. J Nerv Ment Dis. 2008;196:687-693.

16. Lee HY, Choi JK. Pathway to health literacy in Korean American immigrants: The mediating role of English proficiency. J Hum Behav Soc Environ. 2012;22:255-269.

17. Kim SH, Yu X. The mediating effect of self-efficacy on the relationship between health literacy and health status in Korean older adults: A short report. Aging Ment Health. 2010;14:870-873.

18. Coffman MJ, Norton CK. Demands of immigration, health literacy, and depression in recent Latino immigrants. Home Health Care Manag Pract. 2010;22:116-122.

19. Eriksson I, Unden AL, Elofsson S. Self-rated health: Comparisons between three different measures. Results from a population study. Int $\mathrm{J}$ Epidemiol. 2001;30:326-333.

20. Radloff LS. The CES-D scale: A self-report depression scale for research in the general population. Appl Psych Meas. 1977;1:385-401.

21. California Health Interview Survey. CHIS 2007 sample size by county, age and race/ethnicity. Available at http://healthpolicy.ucla.edu/chis/design/ Documents/09_sample_county-race.pdf. Accessed January 122015.

22. California Health Interview Survey. CHIS 2007 sample design description. Available at http://healthpolicy.ucla.edu/chis/design/Documents/sample_ desc 2007.pdf. Accessed January 122015.
23. Kessler RC, Andrews G, Colpe LJ, Hiripi E, Mroczek DK, Normand SL, Walters EE, Zaslavsky AM. Short screening scales to monitor population prevalences and trends in nonspecific psychological distress. Psychol Med. 2002;32:959-976.

24. Samejima F. Estimation of Latent Ability Using a Response Pattern of Graded Scores. (Psychometric Monograph No. 17). Richmond: Psychometric Society; 1969.

25. Winsteps: Multiple-choice, rating scale, and partial credit Rasch analysis, Version 3.65. Available at http://www.winsteps.com/winsteps.htm. Accessed January 122015.

26. Embretson SE, Reise SP. Item response theory for psychologists. Mahwah: Lawrence Erlbaum; 2000.

27. The Commonwealth Fund. The Commonwealth Fund 2006 Health Care Quality Survey. Available at http:/ /www.commonwealthfund.org/Surveys / 2006/The-Commonwealth-Fund-2006-Health-Care-Quality-Survey.aspx. Accessed January 122015.

28. Health Research for Action. Investigating the intersection between health literacy and health plan efficiency. Available at http://www.opa.ca.gov/ Documents/Reports/full-report-health-care-access(HRA).pdf. Accessed January 122015.

29. IBM Corp. Released 2011. IBM SPSS Statistics for Windows, Version 20.0. Armonk, NY: IBM Corp.

30. StataCorp. 2011. Stata Statistical Software: Release 12. College Station, TX: StataCorp LP.

31. Wilson E, Chen AH, Grumbach K, Wang F, Fernandez A. Effects of limited English proficiency and physician language on health care comprehension. J Gen Intern Med. 2005;20:800-806.

32. King AYC, Bond MH. The Confucian paradigm of man: A sociological view. In: Tseng WS, Wu DYH, eds. Chinese Culture and Mental Health. Orlando: Academic Press; 1985:29-45.

33. Uda L. Asian Americans: Personality Patterns, Identity, and Mental Health. New York: The Guilford Press; 1994.

34. Kleinman A. Culture and depression. N Engl J Med. 2004;351:951-953.

35. Kane RL, Radosevich DM. Conducting Health Outcomes Research. Sudbury: Jones \& Bartlett Learning; 2011 